\title{
Artigo
}

\section{A dimensão da autonomia nas práticas de extensão em educação popular}

The dimension of autonomy in extension practices in popular education

La dimensión de la autonomía en las prácticas de extensión en la educación popular.

La dimension de l'autonomie dans les pratiques de vulgarisation dans l'enseignement populaire

Ione Gomes da Silva

Bruno Oliveira de Botelho

Pedro José Santos Carneiro Cruz

Aline Maria Batista Machado

Universidade Federal da Paraíba, Brasil

Recebido em: 30/12/2019

Aceito em: 27/03/2020

\section{Resumo}

O estudo busca analisar a dimensão da autonomia como um dos elementos teórico-metodológicos orientadores dos projetos de extensão em educação popular. Procuramos averiguar a compreensão de estudantes extensionistas sobre a autonomia nos trabalhos, nos cenários de prática e identificar se a autonomia se apresenta como uma das categorias fundamentais. O estudo se caracteriza como uma pesquisa qualitativa. Inferiu-se que, no âmbito do projeto de extensão, há estimulo ao desenvolvimento da autonomia dos discentes, porém ainda é preciso avançar em alguns aspectos para que venha a promover de forma mais satisfatória essa dimensão, especialmente no que se refere a sua promoção na comunidade.

Palavras-chave: Extensão-Popular. Extensão Universitária. Educação Popular. Autonomia. 


\section{Abstract}

The study seeks to analyze the dimension of autonomy as one of the guiding theoretical-methodological elements of extension projects in popular education. We sought to ascertain the understanding of extension students about autonomy at work, in practice settings and to identify whether autonomy is presented as one of the fundamental categories. The study is characterized as a qualitative research. It was inferred that, within the scope of the extension project, there is stimulation to the development of the autonomy of the students, but it is still necessary to advance in some aspects to promote this dimension more satisfactorily, especially with regard to its promotion in the community.

Keywords: Extension-Popular. University Extension. Popular Education. Autonomy.

\section{Resumen}

El estudio busca analizar la dimensión de la autonomía como uno de los elementos teórico-metodológicos rectores de los proyectos de extensión en educación popular. Intentamos determinar la comprensión de los estudiantes de extensión sobre la autonomía en el trabajo, en los entornos de práctica e identificar si la autonomía se presenta como una de las categorías fundamentales. El estudio se caracteriza por ser una investigación cualitativa. Se infirió que, dentro del alcance del proyecto de extensión, existe un estímulo para el desarrollo de la autonomía de los estudiantes, pero aún es necesario avanzar en algunos aspectos para promover esta dimensión de manera más satisfactoria, especialmente con respecto a su promoción en la comunidad. Palabras clave: Extensión popular. Extensión Universitaria. Educación popular. Autonomía.

\section{Resumé}

L'étude cherche à analyser la dimension de l'autonomie comme l'un des éléments directeurs théoriques et méthodologiques des projets de vulgarisation dans l'éducation populaire. Nous avons cherché à vérifier la compréhension des étudiants en vulgarisation sur l'autonomie au travail, dans les milieux de pratique et à déterminer si l'autonomie est présentée comme l'une des catégories fondamentales. L'étude est caractérisée comme une 
recherche qualitative. Il a été déduit que, dans le cadre du projet d'extension, il y a une stimulation au développement de l'autonomie des étudiants, mais il est encore nécessaire d'avancer sur certains aspects pour promouvoir cette dimension de manière plus satisfaisante, notamment en ce qui concerne sa promotion dans la communauté.

Mots-clés: Extension populaire. Extension universitaire. Éducation populaire. Autonomie.

\section{Introdução}

Neste trabalho, procuramos empreender uma reflexão crítica sobre o desenvolvimento da autonomia nas iniciativas de extensão universitária, tanto em sua relação com a formação discente, como no que se refere às ações sociais junto à comunidade.

Como afirmam Cruz e Vasconcelos (2017), é particularmente nas últimas duas décadas que tem sido notável o processo de expansão quantitativa e qualitativa de iniciativas de extensão universitária no país, fenômeno que vem sendo acompanhado pela crescente relevância desse fazer universitário na medida em que a comunidade acadêmica o percebe, cada vez mais, como mobilizador da pesquisa e do ensino com consequência, ressonância e utilidade social. Como destacam Incrocci e Andrade (2018), a noção de indissociabilidade entre pesquisa, ensino e extensão contribui para a emergência de uma concepção ampliada do que seja extensão e, consequentemente, do próprio modo de pensar de fazer as ações universitárias.

[a extensão] deixa de ser apenas um meio para abrir as portas dos Ipes para aqueles que não poderiam ter acesso a eles por outras vias, como era previsto pelos movimentos estudantis, e passa a constituir um elo fundamental na formação do aluno e da produção de conhecimento dentro da universidade. Um elo institucionalizado, dotado de metodologia e avaliação próprias (Incrocci, Andrade, 2018, p.195). 
Paula (2013) assevera a centralidade da extensão universitária como elemento de articulação dialógica permanente da universidade com a sociedade de modo a empenhar coerentemente os esforços de pesquisa e de ensino para responder às suas demandas e expectativas. Para tanto, cabe aos protagonistas das ações extensionistas reconhecer a sociedade e suas diversidades e complexidades, incluindo-se aí a clareza de que os entes dos grupos sociais são compostos por sujeitos de direitos e, fundamentalmente, portadores de valores e culturas tão legítimos quanto aqueles derivados do saber erudito. É

tarefa da extensão construir a relação de compartilhamento entre o conhecimento científico e tecnológico produzido na universidade e os conhecimentos de que são titulares as comunidades tradicionais. É tarefa da extensão a promoção da interação dialógica, da abertura para alteridade, para a diversidade como condição para a autodeterminação, para a liberdade, para a emancipação (Paula, 2013, p.21).

Portanto considerando a potente contribuição dos projetos de extensão para a promoção da autonomia dos sujeitos e dos grupos sociais, por meio da produção do conhecimento e do fortalecimento da interação entre a Universidade e as comunidades, este artigo objetiva analisar a dimensão da autonomia como um dos elementos teórico-metodológicos orientadores dos projetos de extensão em educação popular, tomando como base uma experiência realizada na Universidade Federal da Paraíba (UFPB), averiguando a compreensão de extensionistas dessa experiência sobre a autonomia nos trabalhos, nos cenários de prática e identificar se a autonomia se apresenta como uma das categorias fundamentais.

Compreendemos autonomia como condição sócio-histórica de um povo ou um indivíduo que tenha se libertado, se emancipado, das opressões que restringem ou anulam sua liberdade de determinação. Sendo assim, a autonomia deve ser conquistada, construída a partir das decisões, das vivências, da própria liberdade. Através dos relatos dos estudantes revelamse elementos da construção da sua própria autonomia no âmbito do projeto de extensão e também elementos referentes à construção da autonomia da 
comunidade onde o projeto acontece.

Para uma compreensão mais significativa sobre a dimensão da autonomia dos estudantes, foram realizadas entrevistas semiestruturadas que posteriormente foram transcritas e analisadas por meio do método dialético. A seguir, discorreremos sobre alguns elementos históricos e conceituais da extensão universitária orientada pela concepção da educação popular (a qual denominaremos de extensão popular) e da extensão universitária. Posteriormente, apresentaremos de forma detalhada a metodologia que foi utilizada no estudo e nossos resultados e discussões.

\section{Extensão popular e Extensão universitária: breves considerações histórico- conceituais}

A extensão popular é popular em um sentido de povo, expresso pelas camadas mais baixas, economicamente, da sociedade - os pobres, os trabalhadores do campo e da cidade, os explorados, os oprimidos, os excluídos ou os que vivem da venda da força de seu trabalho. Atividades de extensão no campo popular essencialmente de dimensão educativa, inserem-se nesse marco da produção e tornam-se elementos de socialização dos bens culturais produzidos, podendo contribuir para a identidade e a resistência cultural das classes populares (Melo Neto, 1999).

Em meados da década de 1980, a extensão universitária já havia sido oficializada e até com apoio institucional, considerada como inovadora e progressista, passando a exigir um novo tipo de profissional: mais habilitado para a relação com as comunidades e mais compreensivo em relação aos interesses e à lógica popular. Ministério da Saúde, secretarias de saúde, entre outros setores, todos criaram coordenações no movimento em questão.

Desde a criação do Fórum de Pró-Reitores de Extensão das Universidades Públicas Brasileiras (FORPROEX), em 1987, as concepções de extensão Universitária vêm descontruindo o caráter academicista e tecnicista hegemonicamente construído ao longo das décadas anteriores nas práticas extensionistas, os quais foram denunciados de forma contextualizada e 
crítica em trabalhos como os de Roberto Mauro Gurgel Rocha (1986) - na obra "Extensão universitária: comunicação ou domesticação?" - e de Paulo Freire (1979) - na obra "Extensão ou Comunicação?". Certamente influenciado por tais obras, dentre outros elementos (movimentos, contextos e reflexões), o conceito de extensão universitária construído no I Fórum Nacional de Pró-Reitores de Extensão de Universidades Públicas, em Brasília, considera a extensão como:

Processo educativo, cultural e científico que articula o ensino e a pesquisa de forma indissociável e viabiliza a relação transformadora entre universidade e a sociedade. A extensão é uma via de mão dupla, com trânsito assegurado à comunidade acadêmica que encontrará, na sociedade, a oportunidade de elaboração da práxis de um conhecimento acadêmico. No retorno à universidade, docentes e discentes trarão um aprendizado que, submetido à reflexão teórica, será associado aquele conhecimento. Este fluxo que estabelece a troca de saberes sistematizado, acadêmico e popular, terá como consequência: a produção de conhecimento resultante do confronto com a realidade brasileira regional; a democratização do conhecimento acadêmico e a participação efetiva da comunidade na atuação da universidade. Além de instrumentalizada deste processo dialético de teoria/prática, extensão é um trabalho interdisciplinar que favorece a visão integradora social (BRASIL, 1987, p. 1, apud Melo Neto, 2002, p.15).

Assim, pode-se dizer que o FORPROEX teve um papel muito importante no reconhecimento da extensão universitária pelas instituições de Ensino Superior no Brasil (Koglin; Koglin, 2019), extensão universitária tem se tornado uma valiosa ferramenta para incorporar a importância da retribuição à sociedade que sustenta a academia, não visando levar a universidade a substituir funções de responsabilidade do Estado, mas sim produzindo saberes, tanto científicos e tecnológicos, quanto artísticos e filosóficos, tornando-os acessíveis à população, contribuindo em seu processo de desenvolvimento. De acordo com Stallivieri (2007), em espaços sociais marcados por desigualdades (de distribuição de renda, de despesas com bens de consumo, de serviços, de acesso à saúde e, principalmente, de acesso à educação), a extensão vem ocupando um papel central como 
elemento apoiador de processos de ensino, de pesquisa e de ação social profundamente dedicados ao enfrentamento e à superação dos contextos socialmente injustos e geradores de desigualdades.

Neste percurso, desvelou-se como possibilidade no campo da extensão universitária o conceito de extensão popular (Melo Neto, 2006), como hoje é conhecida, colocando-se como uma perspectiva extensionista distanciada de vertente acadêmicas conservadoras, ou pautadas pelo serviço mercadológico para retorno financeiro ou pelo assistencialismo. O autor compreende a extensão como um trabalho socialmente útil com a intencionalidade de gerar processos de mudança na direção da justiça social. Apesar de se constituir em uma ação desenvolvida há décadas, a denominação extensão popular somente veio a ser consolidada há poucos anos.

Não é apenas uma nova qualificação para a extensão ou apenas outro "jeito de fazer" extensão universitária, mas essa denominação traz consigo uma perspectiva teórica e um recorte epistemológico da extensão (Cruz, 2011), de acordo com os quais as práticas em extensão possuem como objetivo a construção de ações geradoras de autonomia, especialmente nos setores excluídos da sociedade. Conforme Melo Neto (2014), a extensão popular transpõe os muros institucionais, abrangendo ações educativas em movimentos sociais e outros instrumentos organizativos da sociedade civil. Propõe mudanças na Universidade, numa perspectiva educativa democrática, libertadora e, por conseguinte, humanamente ética. É um trabalho social útil, tendo como intenção contribuir significativamente para a transformação da realidade social.

A extensão Popular tem ganhado espaço no ensino superior, como afirmam Vasconcelos e Cruz (2011), mas também, recentemente, em outros cenários como o Sistema Único de Saúde (SUS), conforme apontam Lacerda e Ribeiro, (2011); Silveira e Costa, (2008); (Vasconcelos, Frota e Simon, 2006). Dentre o conjunto multifacetado de dimensões que se apresentam como fundamentais para a constituição do fazer extensão na perspectiva popular, a autonomia se destaca.

A autonomia pode ser considerada o resultado de um árduo caminho educativo. Percorrendo da apatia à libertação e desta à manutenção dos 
conhecimentos e tecnologias atuais para o empoderamento de um indivíduo ou sociedade de forma consciente. Um elemento a ser levado em consideração ao avaliar as intenções de uma extensão popular em seu campo de prática. Podemos considerar que a autonomia é um elemento teórico que indica o principal objetivo de uma prática em extensão popular, socializando uma metodologia educativa comprometida com as causas das mudanças sociais diante dos problemas humanos (Melo Neto, 2002).

Na perspectiva da autonomia, a autogestão apresenta-se como dimensão fundante. Uma sociedade autogestionária é organicamente autônoma, constituída de um feixe de autonomias, de grupos se autoadministrando, cuja vida exige a coordenação, mas não a hierarquização, como afirma Motta (1981). A autogestão se insere na perspectiva de transformação geral da sociedade. São mudanças de ordem intelectual, cultural e moral da classe trabalhadora, inscritas em avanços e recuos profundos, marcando um socialismo que, na sua essência, é a autogestão social, baseada na mais ampla democracia e na hegemonia dos trabalhadores.

Historicamente, a autogestão começa a ser discutida com mais força a partir da década de 1960, através de grupos de estudos, sindicatos, partidos e organizações não governamentais, aparecendo na imprensa e jornais e em vários outros meios de comunicação. Os avanços tecnológicos impulsionados pelo desenvolvimento do modo de produção capitalista têm trazido para as classes populares, ao atingir a base de sua própria existência, diferenciadas formas de reação ao desemprego (Melo Neto, 2005).

Autogestão pode ser compreendida, portanto, como uma forma de promoção da democracia em instituições sociais em que trabalhadores são os sócios e os sócios são os trabalhadores (Singer, 2000). Sendo assim, Melo Neto (2005) afirma que a gerência de qualquer experiência social, na perspectiva da autonomia, deve promover a igualdade de todos os seus membros, bem como a sua completa liberdade. Uma organização que promova a igualdade de seus membros e não careça, assim, da existência de um poder de mando centralizado. As suas normas não necessitam mais estar sob qualquer influência de alguém que seja alheio ao próprio grupo, como o projeto de extensão. A própria organização define as pessoas que irão exercer as diversas atividades, inclusive, a atividade coordenadora, nada centralizada. 


\section{Percurso metodológico}

Para a realização deste estudo, utilizou-se uma metodologia qualitativa. Neves (1996) teoriza que enquanto o estudo quantitativo costuma seguir com rigor um plano previamente estabelecido (baseado em hipóteses claramente indicadas e variáveis que são objeto de definição operacional), a pesquisa qualitativa costuma ser direcionada ao longo de seu desenvolvimento; além disso não busca enumerar ou medir eventos e, geralmente não emprega instrumental estatístico para análise de dados.

A forma de coleta do material empírico se deu por meio de entrevistas individuais, com roteiro semiestruturado. Para Medina (2002), a entrevista, nas suas diferentes aplicações, é uma técnica de interação social, de interpretação informativa, quebrando assim isolamentos grupais, individuais, sociais; pode também servir à pluralização de vozes e à distribuição democrática da informação. A autora acredita que quando o diálogo autêntico acontece, entrevistado e entrevistador saem alterados do encontro.

As entrevistas individuais foram realizadas de forma privada e resguardando o anonimato dos entrevistados, que foram seis (06) estudantes extensionistas de um projeto da UFPB, tendo como critério de inclusão aqueles que acumulavam pelo menos um ano de experiência, priorizando, deste modo, os que participaram por mais tempo.

O roteiro da entrevista foi constituído de seis (06) questões que buscaram explorar a avaliação que os extensionistas pesquisados fazem atualmente sobre alguns pontos chaves, quais sejam: os processos de avaliação ocorridos nos últimos anos no projeto; os aspectos metodológicos do projeto; a clareza da problemática na qual o projeto atua; os indicadores de autonomia estudantil e da comunidade (campo de prática); a qualidade das interações do projeto com a comunidade; e por fim, a resposta obtida pelos protagonistas do Projeto ao longo de suas atividades recentes.

Todas as entrevistas foram transcritas e os pontos-chave selecionados e 
impressos para a leitura exaustiva do material, que nortearam a discussão deste estudo, dialogando a prática com as referências metodológicas utilizadas pelo estudo e pela extensão popular.

A dialética marxista serviu como método de análise para a interpretação lógica e construção do objeto investigado. Fazendo a análise do caráter material e do caráter histórico, isto é, da reprodução da vida no objeto de estudo e a consequente organização humana para esta reprodução, permite a compreensão das leis fundamentais que definem a forma organizativa dos sujeitos em questão durante a história do objeto de estudo.

\section{Resultados e discussão}

De acordo com os relatos dos entrevistados, foi possível inferir que o projeto de extensão analisado, seguindo a linha da extensão popular, democratiza o trabalho realizado em seu corpo estudantil, utilizando de elementos da autogestão para que exista uma fluidez em suas atividades. Em vários momentos, em meio às reuniões, os protagonistas do projeto esclarecem, debatem e encaminham acordos sobre sua metodologia. No entanto, também percebe-se nas falas dos entrevistados um sentimento que merece destaque: os limites da avaliação crítica do projeto de extensão como atividade constituinte de seu planejamento. Esta conclusão pôde ser respaldada em todas as respostas no tocante à metodologia de avaliação do projeto de extensão. Dentre as reflexões, destacam-se:

Não tive a oportunidade de vivenciar muitos processos avaliativos dentro do projeto de extensão. A gente tentou em alguns momentos sentar e avaliar determinada atividade, mas eu acho que a atuação do projeto como um todo dentro da comunidade não foi muito abordado não. [...]. Até quando estava fazendo o relatório final do projeto lá no Probex, tinha uma parte que ele questiona avaliação e aí que a gente percebeu "eita, era pra fazer avaliação junto com a comunidade, junto com os moradores" e a gente percebeu que isso não foi feito, então atuamos o ano inteiro e a parte de avaliação ficou meio defasada. Eu acho que isso é um problema de longo tempo, estou no projeto há 2 anos e nunca nós paramos pra sentar e pensar 
"o que a gente está realmente fazendo lá na comunidade? ou se está certo da maneira que a gente está fazendo (Extensionista entrevistado 1)

Para todos os voluntários, as avaliações são realizadas de forma horizontal, com o ouvir da fala de todos em um momento dedicado a esta prática e tentando destacar as fraquezas e potencialidades das atividades em questão. Porém, como foi explicitada nos depoimentos dos entrevistados, a defasagem de extensionistas que se dispõem a contribuir nestes momentos é significante, o que enviesa parte da qualidade do processo. Neste aspecto, outra questão primária foi destacada por um dos depoimentos:

As avaliações são feitas em roda nas reuniões do próprio projeto, mas são documentadas só em ata. Agora estamos tentando criar um arquivo que por enquanto está meio esquecido. [...] O projeto como um todo tentamos avaliar recentemente, fizemos um instrumento que não ficou legal, conversamos de boca, foi registrado em ata, mas o instrumento, realmente, não ficou legal (Extensionista entrevistado 3)

A ausência do planejamento metodológico para este processo fez com que o esforço de avaliação do projeto fosse limitado em meio a sua tentativa. Corroborando a prática do registro informal por meio da coleta de atas de reuniões, a única avaliação de forma global que o projeto de extensão tentou realizar em pelo menos três anos de trabalho - de acordo com o Extensionista entrevistado 3 - não foi utilizada.

Com relação à clareza metodológica no desenvolvimento das ações, existe boa avaliação dos extensionistas quanto ao projeto. Todos concordam que uma das características proeminentes é o protagonismo estudantil, de uma forma tão expressiva que a metodologia do projeto absorve em grande parte o perfil da sua gestão atual. 
Eu acho que no geral, desde a seleção tentamos deixar claro a metodologia do projeto. Como ele é desenvolvido na comunidade, ressaltamos isso nas entrevistas e nas primeiras reuniões sempre se dedica um espaço pra falar sobre esta metodologia: o que são os grupos operativos, como são as comissões, que desenvolvemos trabalhos nas casas etc. Mas é algo que não é muito amarrado, cada pessoa tem a sua forma de fazer, cada um faz meio que a sua maneira (Extensionista entrevistado 1)

Porém foi unânime que existe um período latente até a percepção desta metodologia e dos benefícios que esta descoberta por conta própria pode trazer, como cita o extensionista entrevistado 5 :

Quando eu entrei, foi um desastre. Fiquei totalmente perdida, não sabia nada de educação popular ou do projeto. Pra quem tá entrando é complicado, quando você vai participando do tema em palestras e congressos, vivenciando, vai clareando mais.

\begin{abstract}
Alguns dos outros depoimentos dialogam com este, entendendo o rigor metodológico sendo suprimido como uma prática comum no projeto, instalada por meio do comodismo (como declarado pelo extensionista entrevistado 4, adiante), além de agravar a evasão dos selecionados nos primeiros meses de prática. Porém, pontos positivos podem ser identificados nesta experiência:
\end{abstract}

Eu acho que o projeto deixa muito a desejar nesta questão da metodologia. É importante a teoria, o estudante quando está se inserindo de fato, aprende com a prática, mas até então eles estão perdidos. No momento não tem um grupo de estudos, um reforço à teoria, no fim, alguns se acham e outros não. (Extensionista entrevistado 2) 
A gente só vai descobrindo mesmo a metodologia do projeto com muito tempo e quando nos damos chance para conhecer. [...] Acho que isso é do projeto há muito tempo e já está inerente. Todo mundo acha que isso faz parte do projeto e não reflete sobre o assunto. (Extensionista entrevistado 4)

Uma dificuldade que eu tive, logo quando eu entrei, foi saber o que eu estava fazendo lá dentro. A gente sempre quer o projeto de mão beijada, mas vamos recebendo aos poucos. No fim, eu acho legal esta metodologia, a gente vai entendendo aos poucos como ele funciona e vai aprendendo a aceitar e gostar. Você é jogado dentro de uma comunidade sem saber o que você vai fazer lá, quem é o pessoal e como funciona, e aí você aprende e vai trazendo o retorno ao projeto do que aprendeu. Acho que é legal as pessoas irem descobrindo o que é o projeto e educação popular aos poucos. (Extensionista entrevistado 3)

Quanto à clareza metodológica por partes dos sujeitos da comunidade - no campo de prática -, os depoimentos foram variados. Embora ressalte o prazer do vínculo afetivo construído entre membros da comunidade e os extensionistas nas atividades de campo, o extensionista entrevistado 5 destaca uma fragilidade: "Pra comunidade, às vezes, não é tão clara esta metodologia. Principalmente pra quem não é visitado, pode ter gente que tem interesse em saber e não tem acesso a nós". Outro depoimento ainda adiciona:

Os moradores da comunidade têm muito disso de gostar de receber os estudantes, até porque as famílias que a gente visita são as mesmas ao longo dos anos, daí eles já conhecem, ou o vizinho recebe visita, eles gostam dessa dinâmica e conhecem, e aceitam numa boa. Porém, algumas famílias não aceitam bem a rotatividade de estudantes, e não aceitam mais visitas porque não quer mais se apegar e ter que deixar de novo. (Extensionista entrevistado 3)

O abandono das famílias após o vínculo foi discutido como um dos agravos 
mais preocupantes do projeto de extensão nos últimos anos, consequente à irresponsabilidade acadêmica na extensão popular, podendo ser melhor esclarecido por Vasconcelos e Cruz (2011) em estudos realizados sobre a educação popular na formação universitária. A grande evasão de estudantes selecionados após os primeiros meses de atividade no projeto também pode ser destacada como uma questão problemática. Porém, as questões relacionadas à desistência dos estudantes não podem ser confundidas com a rotatividade estudantil que é inerente aos projetos de extensão.

É fato que a grande rotação de extensionistas que praticam suas atividades na comunidade é um elemento intrínseco a qualquer projeto de extensão. Toda graduação possui uma temporalidade delimitada e o próprio decurso da formação universitária contém em si, diferentes etapas, aprofundamentos e exigências, os quais certamente influenciam nos níveis de dedicação e de disponibilidade dos estudantes. Em que pese tal realidade, e justamente em função desta, é imprescindível que o protagonista da comunidade esteja consciente desses limites, para que a rotatividade em sua rotina não seja interpretada como abandono do vínculo e do compromisso do extensionista e do projeto com a comunidade, como citado no depoimento do extensionista entrevistado 3. Pouco, entretanto, se esclarece sobre estas metodologias intrínsecas à comunidade.

É importante que o extensionista - realizando o trabalho social comunitário esteja atento para que, nas relações que ali são desenvolvidas, estejam presentes alguns pressupostos necessários à construção da dimensão da autonomia das pessoas e da comunidade enquanto núcleo social, pois para a construção do saber que leva uma comunidade a se autogerir, esta deve estar ciente do papel que ocupa, qual a sua importância e que esteja ciente de um rigor metodológico com o qual pode, ou não, pactuar e atuar. De acordo com Melo Neto (2005), o trabalho realizado que deseja alcançar a autonomia e a autogestão deve ser realizado de forma a afastar a alienação dominante e ser capaz de assumir características geradoras de críticas em seu papel social. O depoimento a seguir destaca que:

Muitas famílias dizem, "eu só recebo na minha casa" e é só aquilo. Participar ativamente do projeto mesmo não tem tanto não. Existem 
algumas pessoas, algumas lideranças na comunidade que sim, mas não é todo mundo não. (Extensionista entrevistado 3)

É importante que o extensionista realizando o trabalho de vinculação pela visita domiciliar esteja atento para que nas relações que ali são desenvolvidas estejam presentes alguns pressupostos necessários à construção do caráter de emancipação e autogestão na comunidade enquanto núcleo social.

Melo Neto (2005) afirma a importância da igualdade de ambos os lados universidade e comunidade. Cada ente com suas propriedades que lhes são singulares, mas tendo a capacidade de colaborar em busca de algo melhor. Caso a comunidade não se sinta participante ativo da atividade realizada, - resultante deste trabalho realizado constituirá uma ação acadêmica voltada apenas a si mesma, com consequências sociais a longo prazo próximas do nulo e longe da sustentabilidade.

A extensão popular precisa ainda evoluir como um todo no tocante ao retorno da conclusão e do material de pesquisa intelectual à comunidade. Melo Neto (2008), novamente, afirma que a devolução dos resultados do trabalho social à comunidade irá caracterizá-la como possuidora de novos saberes ou saberes rediscutidos. Estes podem ser utilizados pelas lideranças comunitárias em seus movimentos emancipatórios e reivindicatórios, conferindo propriedade da interação extensão-comunidade.

É um desafio histórico das atividades de extensão universitária sua capacidade de gerar produtos úteis à mobilização de mudanças nas comunidades e demais espaços sociais de atuação. Quando os entrevistados foram indagados se a comunidade se considera participante ativa do projeto e do conhecimento científico ali gerado, obtivemos os seguintes destaques:

São poucos os moradores que se integram nas atividades do projeto de extensão, e são os poucos que têm uma visão mais política, como a liderança da ACOMAN. [...] Acho que nós fazemos mais parte do cotidiano deles do que eles fazem do nosso. Não sei se devido às dificuldades de estarem se integrando às nossas atividades pelo fato 
de algumas serem fora da comunidade, mas não acho que eles se sentem participantes do projeto não. (Extensionista entrevistado 1)

É muito delicado. Eu já vi várias situações em que parte da comunidade se mostrou totalmente contrária à inserção do projeto nela, enquanto outros o idolatram, mesmo que a idolatria não seja nossa intenção. Mas no geral, acho que não se sentem tão ativos. Acho que não. (Extensionista entrevistado 2)

Foi quase unânime, com exceção de uma resposta, que a Universidade e a comunidade não estão interagindo em proporções iguais. Destacando, entre as questões analisadas, a pouca acessibilidade dos protagonistas comunitários ao campus universitário e, portanto, à parte importante das atividades do projeto de extensão, como as reuniões organizativas, por exemplo.

Freire (1996) descreve que uma das tarefas mais importantes da prática educativa crítica é propiciar as condições em que os educandos ensaiem a prática de assumirem-se enquanto seres históricos, pensantes, comunicantes, transformadores, criadores e realizadores. Nesse sentido, trazer à tona a construção da autogestão relaciona-se com a assunção dos indivíduos não só de si mesmos, como a expressão da luta da autonomia local. Como enfatiza Melo Neto (2005), uma autonomia relacionada ao outro, no sentido de que não se pode ser autônomo sozinho. Uma sensibilização para a autogestão, como capacidade de poder ser gerido por si mesmo, na relação com os demais, de se organizar livremente, fecundando um cotidiano democrático.

Como cita o extensionista entrevistado 2: "O estudante quando está se inserindo de fato, aprende com a prática, mas até então eles estão perdidos. [...] No fim, alguns se acham e outros não". Este depoimento alerta para a evasão de estudantes nos primeiros meses de prática do projeto. O projeto de extensão possui uma carga horária extensa, o que dificulta o processo de adaptação do extensionista a sua dinâmica.

De acordo com os depoimentos, a vivência prolongada no projeto enseja o envolvimento progressivo dos estudantes com a construção da metodologia 
do projeto, e cultiva-se o sentimento de que: "É algo que não é muito amarrado, cada pessoa tem a sua forma de fazer, cada um faz meio que a sua maneira" (Extensionista entrevistado 1). Possibilita-se, então, um ambiente fecundo de participação autônoma. Contudo, tal fala revela também falta de clareza metodológica da ação. Se por um lado a flexibilidade metodológica deixa os participantes à vontade para participar de forma criativa, por outro pode prejudicar o projeto e a própria participação autônoma por não se ter explicitado o caminho de construção do projeto.

Freire (1996) mostra-nos que uma das principais tarefas do educador para com o educando é trabalhar a rigorosidade metódica com quem deve se aproximar dos objetos passíveis de serem conhecidos. É fundamental, para se construir um equilíbrio entre a necessidade de clareza metodológica e uma condução metodológica participativa, que os docentes e coordenadores consigam apoiar um processo de apropriação dos estudantes quanto ao histórico do projeto e aos contextos de suas ações, e, ao mesmo passo, acolher suas inquietações e propostas; dar vez, dar voz e conferir oportunidade do estudante experimentar, construir as ações não apenas com as ideias estabelecidas, mas com algumas de suas próprias ideias e contribuições também.

Trazer à tona a construção da autogestão relaciona-se com a assunção dos indivíduos não só de si mesmos, como a expressão da luta da autonomia local. Uma autonomia relacionada ao outro, no sentido de que não se pode ser autônomo sozinho. Uma sensibilização para a autogestão, como capacidade de poder ser gerido por si mesmo, na relação com os demais, de se organizar livremente, fecundando o cotidiano democrático (Melo Neto, 2005).

No tocante à promoção da autonomia no contexto social onde ocorre o projeto, vários entrevistados concordaram que, na experiência estudada, isso está acontecendo de forma limitada. Segundo os depoimentos, possivelmente na ânsia pelo protagonismo, o extensionista acaba por ocupar protagonismos sociais primários, secundarizando a participação dos atores do contexto comunitário, em processos sociais de lutas, de enfrentamentos e de articulação política com importância.

Para contribuir de forma efetiva com resultados concretos, acaba-se 
fazendo para a comunidade e não com a comunidade. "Tomar a frente, iniciativa, resolver as coisas, isso é ótimo. Mas acho que algumas coisas dentro da comunidade a gente acabou se apropriando demais, tomando a frente demais" (Extensionista entrevistado 1). Pelas falas, observamos que, para evitar prejuízos nas ações do movimento social local, o Projeto acaba por protagonizar uma grande quantidade de atividades de suma importância para o exercício de emancipação e maturação do movimento político.

Um aspecto que aprofunda esse desafio de fazer com está na avaliação de parte dos entrevistados de que "As atividades não têm seguimento, o knowhow não anda sendo repassado com sucesso" (Extensionista entrevistado 5). Pelos depoimentos, percebemos que a ausência do projeto de extensão em um dia de prática não implica que um ator da comunidade protagonize atividades de campo, mas sim no cancelamento do calendário de ações que aconteceriam no dia, conforme o relato abaixo:

[...] alguns momentos, principalmente durante a inserção dos novatos e a seleção, o projeto fica bastante ausente da comunidade. Eu tentaria observar esta procura deles, né. O seu interesse nas atividades promovidas na comunidade. (Extensionista entrevistado 2).

As interações políticas ficaram muito restritas [...] àqueles estudantes que têm mais interesse e afinidade com a área, mas é uma minoria. A maioria dos extensionistas ainda não despertaram para esta prática. O mesmo acontece dentro da comunidade, muitos moradores ainda não despertaram para lutar por seus diretos e deveres. São mais presentes aqueles coligados à ACOMAN, e nem são todos, um grupo de 3 ou 4 pessoas. Isto precisa ser despertado mais, até dentro do projeto, acho que as pessoas não participam por não verem a real importância disto. (Extensionista entrevistado 1).

Assim, os membros do projeto acabaram por promover, conforme as falas, atividades como a arrecadação financeira de apoio para ações sociais locais, até mesmo à composição de comissão eleitoral da atualização da gestão de sua associação de moradores. Em reuniões com entraves com forças governamentais sobre questões do processo de reurbanização da 
comunidade, as falas e os questionamentos mais importantes foram promovidos pelos entes da universidade, enquanto os moradores permaneciam silenciosos. Um dos entrevistados depôs suas reflexões sobre este momento:

[...] Mas chegar lá e só a universidade ficar falando e os moradores calados já não é legal. Não tem um estímulo à autonomia deles, é um estímulo à autonomia NOSSA, mas até que ponto esta relação está sendo benéfica? (Extensionista entrevistado 1).

Esses espaços, em nossa visão, deveriam ser ocupados exclusivamente pela base do movimento social. Uma prática, para ser considerada autogestionária, carece que as relações de trabalho entre os membros não estejam condicionadas a qualquer outro tipo de vínculo de posse dos bens ou de produção que não o estabelecido por todos, como afirma Melo Neto (2005). O autor teoriza que algumas questões presentes na vida da maioria da classe trabalhadora - como altas jornadas de trabalho, desemprego e o incentivo à priorização dos bens materiais pela posse da classe hegemônica - visam por obnubilar questões que transcendem estas dimensões.

Isto exige medidas mais amplas, audazes e também mais realistas que incentivem o protagonismo dos sujeitos do mundo popular. Mesmo que se demore mais para alcançar objetivos e metas, é imprescindível que os atores universitários envolvidos com atividades de extensão priorizem lutar com o povo. Desta maneira, é possível trilhar um caminho na direção da autonomia dos sujeitos no contexto social de atuação da extensão, na direção do desenvolvimento econômico, social e cultural.

A autogestão possui aspectos educativos, detentores de um conjunto de técnicas e de metodologias que contribuem na direção da economia solidária, sendo a educação popular um fenômeno cheio de potencialidades nessa direção. Melo Neto (2005) afirma que pode-se criar ambientes onde acontece o exercício de um poder autônomo. É, contudo, um poder muito concreto, podendo o trabalhador habilitar-se para a sua capacidade de decisão e a sua força de iniciativa para o trabalho. Assim, 
estará se apoderando de instrumentos, de conhecimentos e de poder político capazes de tecer, por meio de uma grande rede, a sua força de superação do sistema estabelecido.

O autor demonstra que a perspectiva autogestionária dos bens econômicos e culturais passa pela sensibilização das classes trabalhadoras e, sobretudo, daqueles que estão em situação de desemprego, evidenciando que é possível o desenvolvimento de atividades fruto da cooperação entre eles próprios e entre todos.

Sobre a relação entre o projeto de extensão e a comunidade, os extensionistas entrevistados declararam:

Eu acho que os dois são muito dependentes ainda, um do outro. Não sei se é o eco desses 16 anos [...]. Eu acho que precisamos trabalhar mais esta autonomia, tentar dar passos mais sozinhos, não é sair, mas a gente precisa dar mais espaço e estimular mais que eles tomem suas próprias decisões, tenham mais autonomia. (Extensionista entrevistado 1)

Se o projeto se desvencilhasse da comunidade, ele andaria pra frente, mas e a comunidade? Porque por mais que o projeto tenha esse objetivo de não deixar a comunidade dependente, eu acho que ela se tornou. (Extensionista entrevistado 2)

Quando se tem o comodismo, fica difícil pros dois lados. Pro projeto é cômodo estar lá. Em 16 anos, com certeza, os dois já se retribuíram muito, mas estamos em um ponto que está uma repetição. Como o projeto tem uma rotatividade de estudantes, é mais difícil que enxerguem isto, mas pra comunidade, já caiu na mesmice e no comodismo. (Extensionista entrevistado 5)

É unanimidade, na percepção dos entrevistados, que após um considerável decurso de tempo de atividades, já próximo de duas décadas, a comunidade não está em condições de autogerir-se. As raízes desta afirmação remetem às dificuldades no trabalho de autonomia em meio ao 
cotidiano do projeto. Quando questionados a respeito dos indicadores desta autonomia no campo de prática e como identificar o momento em que poderia se iniciar um desligamento do projeto com sustentabilidade das ações, ficou claro que os estudantes não possuíam conhecimento para tal questão e nunca haviam feito um debate sobre o tema em suas práticas, logo preferiram não opinar ou deram respostas bastante dúbias e às vezes até evasivas.

O zelo que o projeto tem pelo vínculo familiar é retratado nas falas dos entrevistados através de seu compromisso com as pessoas, seus contextos sociais e as dinâmicas familiares. Dimensões práticas, como a escuta profunda e a luta pelo estabelecimento de serviços sociais públicos de qualidade na comunidade, demonstram todo o cuidado ético e humano do projeto e de seus atores. Em muitas falas dos entrevistados e em muitas atividades do projeto, notamos que o vínculo afetivo com as pessoas do mundo comunitário é muito caro a todos.

É o combustível que motiva a todos a seguir em um trabalho árduo, de construção de possibilidades, saídas e alternativas em um contexto marcado por exclusões e precariedade. Vejamos, por exemplo, este depoimento:

Então, eu acho que neste momento a comunidade não está preparada para deixar o projeto, mas eu também acho que o projeto não está preparado para deixar a comunidade. Eu não me sinto preparada para deixar 0 projeto, por mais que tenha outras demandas, quando eu penso "não vou ter mais minha família, minhas visitas..." não! Eu tenho que ir de qualquer jeito. Então eu não me sinto preparada para deixar o projeto. Eu não imagino o projeto como um todo deixando a comunidade, com uma história bonita, um vínculo muito grande. (Extensionista entrevistado 1)

A análise crítica possibilitada por este estudo evidencia, a nosso ver, os desafios necessários para a qualificação do trabalho de extensão e para os estudantes participantes, de modo a aprimorar as potencialidades das práticas extensionistas. 
Freire (1996), ao relatar sobre a pedagogia no que tange ao respeito ao educando e na coerência dos educadores, diz que as raízes mais profundas da politicidade na educação se acham na educabilidade do ser humano, que se funda na sua natureza inacabada da qual acabou se tornando consciente.

Como seus protagonistas, um projeto de extensão em educação popular como o estudado também tem seus inacabamentos. É importante estarmos cientes de que ambos, os educandos e educadores, estão inacabados e que em suas relações existe uma ciranda, circulando e embaralhando seus papéis. Daí vem a necessidade de nos avaliarmos, com rigor metodológico.

\section{Considerações finais}

Diante do exposto, consideramos que apesar dos esforços empreendidos na execução do projeto de extensão, este ainda precisa avançar em alguns aspectos para promover de fato a autonomia da comunidade onde é realizado. As falas de alguns entrevistados levantam questões relevantes sobre a forma de execução do projeto, e como isso, de certa forma, contribui ou dificulta o desenvolvimento da autonomia das pessoas da comunidade.

Fica evidente que alguns aspectos de como é realizada a experiência de extensão, nesse caso específico, poderiam ser modificados. Por exemplo, com uma maior interação entre a comunidade e a própria universidade, onde as pessoas tivessem um papel mais ativo e menos passivo.

Outro aspecto relevante que pode e deve ser estimulado nas experiências de extensão é a autogestão das comunidades. Sua autonomia em relação ao próprio projeto de extensão. No projeto analisado, ficou bastante claro através da fala dos entrevistados que os estudantes são bastante estimulados a desenvolver sua própria autonomia, sua autogestão com relação as suas atividades no projeto, porém o mesmo não acontece com a comunidade.

Nesse sentido, o lugar de protagonista que deveria ser ocupado por membros da comunidade acaba sendo ocupado por membros do projeto de extensão. As respostas aos estímulos políticos feitos à comunidade ainda 
se mostram incipientes, pois não há busca pela conquista da autonomia. Desta forma, acreditamos que é relevante procurarmos alternativas práticas para potencializar essa busca no âmbito das experiências de extensão.

Tornar-se autônomo significa ser capaz de tomar as suas próprias decisões de forma consciente e responsabilizar-se por elas. Uma pessoa ou comunidade que conquiste sua autonomia será também uma pessoa ou comunidade empoderada, com força para lutar pela concretização dos seus direitos e conquistar seus objetivos coletivos e individuais.

Nesse sentido, retomamos a ideia da autogestão, e a relevância da sua inclusão nas práticas dos projeto de extensão, pois acreditamos que uma sociedade autogestionária, além de autônoma, terá desenvolvido também habilidades intelectuais e culturais, trazendo muitos benefícios a todos os seus membros.

Para mais, acreditamos que este estudo pode contribuir e motivar um debate maior sobre "Autonomia e Extensão Popular", repercutindo, por exemplo, em iniciativas para identificar a autonomia nas práticas de extensão, averiguando se é efetivamente possível pensar em indicadores para os processos de autonomia pela Extensão Popular.

\section{Referências}

Brasil. (2012). Política Nacional de Educação Popular em Saúde no Sistema Único de Saúde. Ministério da Saúde. Secretaria de Gestão Estratégica e Participativa. Comitê Nacional de Educação Popular em Saúde.

Cruz, P. J. S. C. (2011). Extensão Popular: a reinvenção da univsersidade. In:

Vasconcelos, E.M.; Cruz, P.J.S.C. (Org.). Educação Popular na Formação Universitária; reflexões com base em uma experiência. led. Hucitec.

Cruz, P.J.S.C., \& Vasconcelos, E.M. (2017) Caminhos da aprendizagem na extensão universitária: reflexões com base em experiência na Articulação Nacional de Extensão Popular (ANEPOP). Hucitec.

Fórum de Pró-Reitores de Extensão das Universidades Públicas Brasileiras

(Org). (2007). Coordenação Nacional do FORPROEX.

https://www.ufmg.br/proex/renex/images/documentos/Organizacao-e-

Sistematizacao.pdf

Freire, P. (1979). Extensão ou comunicação? 2a edição. Paz e Terra, 
Freire, P. (1996). Pedagogia da Autonomia - Saberes Necessários à Prática Educativa. $36^{a}$ Edição. Paz e Terra.

Incrocci, L.M. de M.C., Andrade, T.H.N. de. (2018). O fortalecimento da extensão no campo científico: uma análise dos editais ProExt/MEC. Sociedade e Estado, 33(1), 187-212. https://doi.org/10.1590/s0102699220183301008

Koglin, T. S. S., Koglin, J. C. O. (2019). A importância da extensão nas Universidades brasileiras e a transição do reconhecimento ao descaso. Revista Brasileira de Extensão Universitária, 10(2), 71-78.

https://doi.org/10.24317/2358-0399.2019v10i2.10658

Lacerda, D. A. L., Rlbeiro, K. S. Q. S. (2011). Fisioterapia na Comunidade. 1. ed. UFPB-Editora Universitária.

Medina, C. A. (2002). Entrevista o diálogo possível. Ed. Ática.

Melo Neto, J. F. (2002). Extensão Universitária: bases ontológicas. In.:

Extensão Universitária - diálogos populares. Editora da UFPB.

Melo Neto, J. F. (2006). Educação Popular em Economia Solidária. In: XIX

Reunião Anual da Associação Naional de Pesquisa em Educação,

Caxambu - MG.

Melo Neto, J. F. (2008). Educação Popular - sistema de teorias

intercomunicantes. In: José Francisco de Melo Neto; Agostinho da Silva

Rosas. (Org.). Educação Popular - enunciados teóricos. 1ed. Editora da Universidade Federal da Paraíba, v. 1, p. 15-35.

Melo Neto, J. F. (2005). Autogestão. In: Cadeiras, C. N. B.; Macdonald; J. B.;

Melo Neto, J. F. (Org.). Economia solidária e autogestão: ponderações

teóricas e achados empíricos. 1ed. Edufal.

Melo Neto, J. F., Lima, L. M. S., \& Araújo, I. C. M. (2005). Educação popular e trabalho - valores éticos fundantes da educação popular nas práticas pedagógicas em cursos profissionalizantes da Usina Catende-PE. In: V Colóquio Internacional Paulo Freire - desafios à sociedade multicultural. Recife - PE: Universidade Federal de Pernambuco.

Melo Neto. J. F. (1999). Extensão popular e ética. Anais do XIV Encontro de pesquisa educacional do Norte e Nordeste. Universidade Federal da Bahia.

Motta, F. C. P. (1981). Burocracia e autogestão: a proposta de Proudhon. Brasiliense.

Neves, J. L. (1996). Pesquisa Qualitativa - Características, Usos e Possibilidades. Caderno de pesquisas em administração. São Paulo, 1 (3). Paula, J. A. (2013). A extensão universitária: história, conceito e propostas. Interfaces - Revista de Extensão, 1 (1), 5-23, Belo Horizonte.

https://periodicos.ufmg.br/index.php/revistainterfaces/article/view/18930 $\angle 15904$

Rocha, R. M. G. (1986). Extensão universitária: comunicação ou domesticação? Cortez Editora/Editora Autores Associados/Edição UFC. 
Silveira, J. L. G. C., \& Costa, L. H. (Org.). (2008). Liga de Saúde Coletiva Extensão Popular em Busca da Integralidade. 1. ed. EDIFURB.

Singer, P. (1998). Uma utopia militante. Repensando o socialismo. Vozes. Stallivieri, L . (2007). O sistema de educação superior do Brasil.

Características, tendências e perspectivas. Universidades, 34, 47-61. https://www.ucs.br/site/midia/arquivos/sistema ensino superior.pdf

Vasconcelos, E. M. (2011). Educação Popular na Universidade. In:

Vasconcelos, E.M.; Cruz, P.J.S.C.. (Org.). Educação Popular na Formação Universitária; reflexões com base em uma experiência. led. Hucitec. Vasconcelos, E.M., \& Cruz, P.J.S.C. (Orgs.). (2011). Educação popular na formação universitária: reflexões com base em uma experiência.

Hucitec; Editora Universitária da UFPB.

Vasconcelos, E.M., Frota, L.H., \& Simon, E. (2006). Perplexidade na universidade: vivências nos cursos de saúde. Editora Hucitec.

\section{Biografia}

\section{Ione Gomes da Silva}

Pedagoga pela Universidade Federal da Paraíba. Mestranda em Educação - PPGE/UFPB. Integrante do Grupo de Pesquisa em Extensão Popular EXTELAR/UFPB/CNPq.

E-maill: ionegs89@gmail.com

ORCID: http://orcid.org/0000-0002-1287-4245

\section{Bruno Oliveira de Botelho}

Fisioterapeuta pela Universidade Federal da Paraíba. Doutorando em Modelos de Decisão e Saúde pela Universidade Federal da Paraíba. Integrante do Grupo de Pesquisa em Extensão Popular - EXTELAR/UFPB/CNPq. E-mail: brunoobotelho@gmail.com ORCID: http://orcid.org/0000-0003-4150-0223

\section{Pedro José Santos Carneiro Cruz}

Doutor em Educação - PPGE/UFPB. Professor do Departamento de Promoção da Saúde do Centro de Ciências Médicas da Universidade Federal da Paraíba. Integrante do Grupo de Pesquisa em Extensão Popular EXTELAR/UFPB/CNPq

E-mail: pedrojosecruzpb@yahoo.com.br 
ORCID: http://orcid.org/0000-0003-0610-3273

\section{Aline Maria Batista Machado}

Doutora em Educação - PPGE/UFPB. Professora do Curso de Serviço Social da Universidade Federal da Paraíba - UFPB. Coordena o Grupo de Estudos e Pesquisas em Educação Popular, Serviço Social e Movimentos Sociais (GEPEDUPSS).

E-mail: prof.alinemachado23@yahoo.com.br

ORCID: http://orcid.org/0000-0002-1144-6011

\section{(c) (1)}

Licença Creative Commons. Este trabalho está licenciado sob uma Licença Internacional Creative Commons Attribution 4.0 . 